\title{
ABDOMINAL SUSPENSION OPERATION FOR UTERO-VAGINAL PROLAPSE USING AUTOLOGOUS FACIAL SLING OF RECTUS SHEATH
}

\author{
Rahat-un-Nisa and Zahida Perveen \\ Department of Obstetrics \& Gynaecology, Ayub Hospital Complex Abbottabad
}

\begin{abstract}
Background: Our purpose was to evaluate the result of abdominal suspension operation using an autologous facial sling for uterovaginal prolapse. Methods: Retrospective case record analysis was performed of total of 16-young patients with low parity at Women and Children Hospital Abbottabad, from 1993-1998. They were followed up to 5 years on an average. Results: All 16 patients except one were successful, two patients got pregnant and had vaginal deliveries without any complication or recurrence. Conclusions: This procedure is less time consuming with negligible blood loss and has good results.
\end{abstract}

\section{INTRODUCTION}

Uterovaginal prolapse is one of the commonest complaint in female population presenting in out patient gynaecology clinics specially of under developed countries. Previously we had 3 or 4 techniques to correct this entity. We had anterior colporaphy and colpoperineoraphy, Manchester repair, vaginal hysterectomy, colpoclesis and Leforts' operation. But these operative techniques are not ideal for a young lady who wants to retain her reproductive functions and at the same time to be free of symptoms. In such patients recommended operation is Manchester repair but long term impacts on future fertility are not that good. Abdominal suspension operation is comparatively new technique. In this we formed a pedicled facial strip for the suspension of prolapsed uterus and stitched it to the posterior aspect of the supravaginal portion of the cervix, medial to the attachment of uterosacral ligament. A merceline tape, nylon or prolone can also be used for this purpose.

\section{MATERIALS AND METHODS}

The case records of 16 women who had been treated by this technique were reviewed. All these women had second degree uterine prolapse with variable length of cervix and uterus $(2-7 \mathrm{~cm})$ lying out side the introitus. Most of the patients were young. Three were unmarried, ten were under 30 years and 2 were 40 years old. All were with low parity and incomplete family. Three were nulliparous. 6 were para I and rest were with higher parity but with incomplete family. Three patients had decubitus ulcer, 4 had stress incontinence and all 16 had cystocoele and rectocoele.

The women were placed in supine position. Abdomen was opened through a Pfannensteil incision. Dissection were carried out up to rectus sheath. Horizontal incision was made in rectus sheath approximately $15 \mathrm{~cm}$ in length. This length can be changed according to the degree of prolapse and surgeon's need. Left limb of the sling approximately $1 \mathrm{~cm}$ in width was harvested from the lower edge of apponeurosis starting from the midline of the incision and separated latterly up to the lateral border of rectus muscle till the internal inguinal ring was exposed. Right strip was also made in similar way and both strips were held in clamps on each side. Peritoneal cavity was opened. Internal organs were inspected, a small transverse incision was given in to the peritoneum posteriorly at supravaginal portion of the cervix near to the attachment of uterosacral ligament. A long curved artery clamp was passed through this incision in to the broad ligament to the internal inguinal ring using round ligament as a guide.



Figure-1

The facial strips were carried between the leaves of broad ligament and attached to the supra vaginal portion of the cervix posteriorly with a non absorbable suture i.e. black silk No.1 using $40 \mathrm{~mm}$ curved round body needle on both sides. At the end of procedure the uterus is lifted up and is bent anteriorly along its long axis. Abdomen closed in usual way with special reinforcement at the level of 
internal inguinal rings. Post-operatively cough and constipation was prevented.

\section{RESULTS}

There were no complication post-operatively in all cases. Blood loss was negligible. Post-operative recovery were uneventful in all patients. One patient had bad persistent cough due to chronic bronchitis post-operatively.

On discharge speculum examination of all patients was performed and cervix was found at or above the level of ischial spines except in one patient in whom procedure failed due to persistent cough post-operatively.

In majority of the patients cystocoele and rectocoele automatically got corrected and in few patients stress incontinence also got corrected surprisingly.

On latter fallow up, up to 5 years three patients got pregnant and delivered vaginally and after peurperium there were no sign of prolapse.

Table-1: Patients profile: symptoms

\begin{tabular}{|l|c|}
\hline Symptoms & No. Of Patients \\
\hline Second degree uterine prolapse & 16 \\
Cystocoele & 16 \\
Rectocoele & 16 \\
Decubitus ulcer & 02 \\
Stress Incontinence & 04 \\
\hline
\end{tabular}

Table-2: Patients Profile:- Age in Years

\begin{tabular}{|c|c|c|c|c|}
\hline $\begin{array}{c}\text { Upto 20 } \\
\text { years }\end{array}$ & $\begin{array}{c}\mathbf{2 1 - 2 5} \\
\text { years }\end{array}$ & $\begin{array}{c}\mathbf{2 6 - 3 0} \\
\text { years }\end{array}$ & $\begin{array}{c}\mathbf{3 1 - 3 5} \\
\text { years }\end{array}$ & $\begin{array}{c}\mathbf{3 6 - 4 0} \\
\text { years }\end{array}$ \\
\hline 02 & 04 & 04 & 04 & 02 \\
\hline
\end{tabular}

Table-3: Patients Profile: Parity

\begin{tabular}{|c|c|c|}
\hline Nulliparous & P.1 & $\begin{array}{c}\text { Multiparous with } \\
\text { incomplete family }\end{array}$ \\
\hline 3 & 6 & 7 \\
\hline
\end{tabular}

\section{DISCUSSION}

In these cases we used posterior approach for the attachment of facial sling. Anterior approach i.e. attaching the facial sling to the supravaginal portion of the cervix anteriorly after dissecting and pushing down the urinary bladder is also being used. We used posterior approach and merits for this technique are as follows:

It is less time consuming. It takes approximately 3040 minutes on an average and is an easy operation.

It has less blood loss and is with out any risk of bladder injury.

Moreover if you have to do cesarean section latter on in such patients, there would be no risk of cutting the facial strips.

In patients with marked prolapse one has to dissect the bladder deeper down to correct the prolapse; and this will create oozing and bleeding at bladder base, and sometimes haematoma formation.

Moreover stitches at bladder base will cause constant bladder irritation and urinary problem. While using posterior approach one can go deeper down with out any risk.

In those patients having previous pelvic surgery i.e. cesarean section or anterior and posterior repair of vagina, there will be more technical difficulty in using anterior approach. In such cases posterior approach will be the ideal.

\section{SUGGESTIONS}

This technique may also be suggested for those patients having utero vaginal prolapse but who cannot tolerate prolong anaesthesia and blood loss. These patients should be evaluated properly and should not have any uterine pathology.

\section{REFERENCES}

1. Barrington JW; Calvert JP. Vaginal vault suspension for prolapse after hystrectomy using an autologous facial sling of rectus sheeth. BR-J-Obstet and Gynaecol; 105(1):83-6. 1998Jan.

2. Embrey MP. An abdominal sling operation for the repair of enterocoele and vault prolapse. J Obstet Gynecol. Br. Emp. $1961 ; 68: 471$.

3. Gilliam DT. Round Ligament ventro suspension of the uterus: A new method. Am J. Obstet 1900; 41:299.

4. Hendee AE, Berry CM. Abdominal sacropexy for vaginal vault prolapse. Clin obstet Gynecol. 1981; 24:1217 